\title{
O fórum on-line e a interação em um curso a distância *1
}

\author{
Erlinda Martins Batista. \\ Shirley Takeco Gobara. \\ ebb@nin.ufms.br, gobara@dfi.ufms.br \\ Universidade Federal de Mato Grosso do Sul - UFMS
}

\begin{abstract}
Resumo
Este artigo discute as interações vivenciadas por professores e alunos nos fóruns on-line do curso de pós-graduação lato sensu Orientação Pedagógica em Educação a Distância - EAD. Trata-se de um recorte de uma pesquisa qualitativa - estudo de caso, cujo objetivo foi investigar o papel do fórum on-line no curso mencionado. Os resultados, obtidos pelas análises das entrevistas com professores e alunos e das observações das interações ocorridas, indicaram que as interações ocorridas nos fóruns entre professores e alunos foram insuficientes. Concluiu-se que as concepções de utilização do fórum são inadequadas porque a maioria dos professores utilizou-o apenas como repositório de atividades e não privilegiou suas potencialidades como um espaço de interações para a construção do conhecimento.
\end{abstract}

Palavras-chave: interação, fórum on-line, educação a distância.

\section{On-Line forum and interaction in a distance course2}

\begin{abstract}
The object of this article is to discuss the interactions between teachers and students in online forums of the lato sensu post-graduation course "Orientação Pedagógica em Educação a Distância - EAD" (Pedagogical Orientation in Distance Learning). This is a case study linked to a programme of Post-graduation in Education, whose aim was to investigate the role of on-line forums. Results indicated that the interactions between teachers and students and observations of interactions were insufficient. Thus, it may be concluded that the conceptions of forum utilization are inadequate because most teachers made use of it only as a repository of activities and did not explore its potentialities as a space of interactions aiming at knowledge construction.
\end{abstract}

Key words : interaction, on-line forum, distance learning

\section{Introdução}

O presente artigo discute aspectos fundamentais do processo de interação, vivenciado pelos professores e alunos, observados nos fórum on-line de um curso de pós-graduação

1 Artigo extraído da dissertação intitulada: "O papel do fórum on-line em um curso de pós-graduação lato sensu a distância: um estudo de caso".

2 Article extracted from a dissertation entitled The role of on-line forum in a lato sensu post-graduation distance course - a case study. 
lato sensu Orientação Pedagógica em Educação a Distância, em sua terceira edição, de uma instituição pública de ensino superior. Trata-se dos resultados de uma pesquisa qualitativa, do tipo estudo de caso, concluída em 2006, cujo objetivo foi investigar, no curso mencionado, o papel do fórum on-line.

O papel do fórum on-line revelou-se importante porque é um espaço em que efetivamente as interações devem ocorrer, o que, entretanto, não aconteceu plenamente em função das dificuldades evidenciadas, por professores e alunos, ao longo do curso.

Entre estas dificuldades destaca-se a interação precária observada, e que foi uma das hipóteses de pesquisa levantada e ao final confirmada.

As análises das entrevistas com professores e alunos e das informações obtidas nos fóruns das disciplinas do curso sugerem que as poucas interações observadas são decorrentes de uma formação pouco especializada dos docentes e de práticas presenciais tradicionais. Além disso, verificou-se que há entre os sujeitos investigados, certo desconhecimento das potencialidades do fórum on-line como um instrumento virtual de aprendizagem, adequado para promover a interação e a construção do conhecimento de forma colaborativa nesse contexto.

A compreensão do significado e relevância da interação em um ambiente virtual de aprendizagem e as concepções de utilização do fórum on-line, no entendimento de professores e alunos investigados, foram analisadas sob a visão de pesquisadores e teóricos atuais da educação a distância, como Moran (2002, 2003, 2006), Almeida (2003), Belloni (2001), Palloff e Pratt (2004), etc. As análises das interações ocorridas no fórum on-line foram embasadas principalmente no conceito de interação discutido por Vigotsky (2000), e subsidiadas pelas definições de situações didáticas e contratos didáticos de Brousseau (1996) e Chevallard (2001).

\subsection{Fórum on-line: a construção de seus significados}

A palavra fórum tem diferentes definições, podendo significar: Fórum jurídico, Fórum Humorístico, Fórum de discussão, entre outros. No latim: forum - é algo que permite o movimento (Ferreira, 1999: p. 932). O fórum é, também, conceituado como sendo uma reunião, congresso, ou conferência para debate de um tema (Houaiss, 2004). Fórum3 significa um encontro público para discussão aberta. Dessas últimas idéias surgem os fóruns virtuais de discussão utilizados em ambientes de aprendizagem on-line e off-line.

Estes fóruns podem ser de dois tipos: fóruns gerais e fóruns de grupo. Em ambos, o fórum é um ambiente virtual de aprendizagem e serve de apoio ao professor para se discutir temas de estudo do curso (Moran, 2004).

Os recursos dos ambientes virtuais de aprendizagem são os mesmos da Internet, correio, fórum, Chat etc., (Almeida, 2003). Por outro lado, Preece (2000), citada por Palloff e Pratt, (2004: p.37), destaca que se os recursos utilizados tiverem a função de apenas apresentar a informação aos sujeitos não se pode considerar o ambiente virtual uma sala de aula on-line, nem uma comunidade de aprendizagem on-line4.

\footnotetext{
3 “... A public meeting place for open discussion”. Disponível em: http://www.thefreedictionary.com/Forums. Acesso em: 01 agosto e 2006.

${ }_{4}$ Comunidade de aprendizagem on-line é definida por Palloff e Pratt (2004) como um grupo de pessoas, professores, alunos e cordenação com um objetivo comum de realizar uma aprendizagem permeada por uma prática reflexiva, com políticas (diretrizes de curso) comuns e um sistema computacional (um site onde se hospeda o curso on-line).
} 
Para que o fórum on-line e os demais recursos virtuais de aprendizagem cumpram a sua função que é a de permitir uma efetiva interação entre os sujeitos presentes no ambiente online e que possibilite a construção do conhecimento pelo aluno, mediada pelo professor, todas as suas potencialidades devem ser conhecidas pelos usuários desse ambiente.

\subsection{A interação em ambientes virtuais}

_A interação é fundamental para a organização do pensamento acerca de um problema de forma mais elaborada, lógica e analítica, e possibilita a mediação dentro de um grupo orientado pelo professor ou por membro mais experiente desse meio (Vigotsky, 2000).

Para haver a interação em um fórum on-line é preciso dois ou mais sujeitos. A interação é uma ação de reciprocidade entre pessoas que pode ser direta ou indireta (mediatizada por algum veículo técnico de comunicação) na definição sociológica de Belloni (2001).

Mas a presença de professores e alunos nesse meio, só garante a interação se houver por parte desses sujeitos uma concepção que vá além da idéia, muito difundida, de fórum como uma ferramenta virtual para depósito de atividades.

Mais do que na educação presencial, a interação entre professores e alunos na educação a distância é relevante para a manutenção do interesse dos alunos. O fórum por si mesmo não promove a interação. Essa só pode ser efetivada a partir da intencionalidade dos professores e alunos associada a um objetivo maior que é o alcance do conhecimento. A pesquisa realizada apontou a relevância das interações no fórum online, o que justifica esse artigo.

Outro aspecto a ser considerado para que a aprendizagem se realize, em ambientes digitais, nas diferentes situações didáticas diz respeito às regras estabelecidas no contrato didático (Brousseau, 1986, citado por Silva B, 2002). As regras do contrato didático permitem aos sujeitos da situação, professores e alunos, interagirem com o objeto da aprendizagem - o conhecimento (Chevallard, 1988, citado por Silva B, 2002).

\section{Metodologia}

As investigações foram orientadas pela metodologia da pesquisa qualitativa. Os 10 professores e 53 alunos do curso de pós-graduação citado, foram entrevistados e observados no fórum on-line, no período de fevereiro de 2004 e junho de 2005. O fórum on-line estudado foi desenvolvido por dois professores do curso. Eles utilizaram, para a criação do fórum, ferramentas desenvolvidas em software livre, entre elas o sistema operacional Linux, o banco de dados Mysql e o processador de scripts PHP. Os scripts do fórum tiveram como base o $w$-Agora5, um sistema de publicação e gerência de fórum na web.

As dez disciplinas do curso foram disponibilizadas no ambiente on-line duas a duas para cada período de dois meses. Cada disciplina do curso teve um fórum on-line, sendo seus conteúdos disponibilizados ao mesmo tempo. A aula presencial de cada disciplina ocorreu um dia após a apresentação dos conteúdos no ambiente on-line. Os fóruns ficaram ativos por mais 30 dias após o encerramento da disciplina.

${ }_{5}$ Esse software está disponível em: http://w-agora.net/en/index.php. Acesso em 06 de agosto de 2006. 
Nas entrevistas com os professores, utilizou-se um roteiro, com 10 perguntas semiestruturadas e alguns critérios relativos à conclusão ou não da disciplina. Para as entrevistas com os alunos usou-se um questionário de 10 questões semi-estruturadas. As observações nos fóruns foram feitas a partir das participações registradas.

As análises detalhadas das respostas dos professores foram realizadas a partir das informações obtidas nas transcrições das entrevistas. Utilizou-se letras de A a J para identificar cada docente. As análises gerais, dadas pelo cruzamento dos resultados das análises detalhadas, associadas aos resultados das observações foram subsidiadas pela fundamentação teórica do interacionismo de Vigotsky (2000), a noção de contrato didático de Brousseau (1976), Chevallard (2001), e pelas idéias de Belloni (2001), Moran (2002, 2003 e 2006), e Almeida (2003), no que se refere às interações vivenciadas nas situações didáticas observadas nos fóruns.

\section{Análises das interações e resultados}

No sentido de evidenciar o processo de interação entre os professores e os alunos do curso, foram analisadas 03 questões das entrevistas com os professores e 01 questão da entrevista com os alunos.

\subsection{Análises dos Resultados das Entrevistas com os Professores}

Entre as questões apresentadas aos professores, e para possibilitar as análises das interações no fórum on-line, escolheu-se, para apreciação nesse artigo, as questões 01,02 e 08 . Os resultados da primeira questão (Tabela 1) mostraram que 2 (dois) professores não haviam utilizado o fórum antes do curso. Eles não tinham experiências no uso do fórum e nem a formação relacionada à dimensão tecnológica necessária para o uso do recurso.

\section{Tabela 1 - Questão 1:Você já fez uso do fórum em outras disciplinas?}

\begin{tabular}{l|c|c} 
Resposta & Prof. & $\%$ \\
\hline SIM & 08 & 80 \\
\hline NÃO & 02 & 20 \\
\hline Total & 10 & 100
\end{tabular}

A formação dos professores de EAD segundo Belloni (2001) deve ocorrer nas três dimensões fundamentais: pedagógica, didática e tecnológica. $\mathrm{O}$ fato de 02 (dois) docentes inexperientes no uso do fórum on-line terem sido selecionados para atuar no curso pode ser interpretado por duas vias: 1) a seleção priorizou outros aspectos da formação desses docentes; 2) não houve critério quanto a exigência de experiência em ambientes on-line. Problemas dessa natureza podem ser remediados se a organização do curso preparar ou capacitar o professor para trabalhar com tecnologias educacionais e realizar reflexões sobre o papel desses recursos, no caso, o fórum, e sobre a relevância da participação do docente como mediador e incentivador da interação nesse ambiente (Palloff e Pratt, 2004). Caso contrário, a capacitação é inócua e pode reproduzir concepções de uso inadequadas.

Constatou-se que 05 (cinco) professores possuíam prática em EAD, mas não tinham curso ou formação acadêmica específica para atuar nessa modalidade de educação, 03 (três) tinham experiência e formação na modalidade da EAD, 01 (um) não tinha prática nem preparação acadêmica para atuar na EAD e 01 (um) tinha formação acadêmica, mas não 
tinha prática docente em EAD. As análises destes dados evidenciam que dos 10 (dez) professores entrevistados, 05 (cinco) não estavam adequadamente preparados para atuar no curso investigado. As observações e análises dos registros contidos nos fóruns mostraram que a pouca interação observada, pode ser decorrente desse despreparo admitido pelos próprios professores do curso.

A segunda questão (Tabela 2) buscou verificar as dificuldades dos professores. Dos 07 (sete) que responderam afirmativamente, 02 (dois) não utilizaram o fórum on-line durante todo o curso; os outros 05 (cinco) apenas postaram mensagens. Quanto aos 3 (três) que afirmaram não enfrentar dificuldades, verificou-se um reduzido número de mensagens nos fóruns de suas respectivas disciplinas.

\section{Tabela 2 - Questão 2: Você teve dificuldades ou venceu falhas na utilização do}

\section{fórum?}

\begin{tabular}{l|c|c} 
Dificuldades & Professor. & Percentagem $(\%)$ \\
\hline SIM & 07 & 70 \\
\hline NÃO & 03 & 30 \\
\hline Total & 10 & 100
\end{tabular}

A análise das duas primeiras questões (questões 01 e 02) mostrou que, embora 08 (oito) tenham afirmado que já haviam utilizado o fórum, apenas 3 (três) afirmaram não encontrar dificuldades. Entretanto, verificou-se pela observação do ambiente e pelas respostas nas entrevistas, que 09 (nove) professores não dominavam o uso do fórum, portanto, não estavam preparados para utilizar o fórum on-line. Uma professora interagiu mais do que todos, ao postar um maior número de mensagens, ao mesmo tempo em que incentivou os alunos ao uso da réplica e tréplica. Ela também afirmou que teve dificuldades e que o fórum é um meio a mais de comunicação com os alunos.

Segundo Pratt e Palloff (2004), o professor deve estimular a participação do aluno no ambiente on-line buscando "sustentar a interatividade do curso on-line" (p.47). Entre os professores observados, a maioria não sustentou essa interatividade. Houve mensagens de alunos reclamando da falta de respostas de alguns professores às suas dúvidas. Essas mensagens somadas às poucas interações observadas evidenciam que esses professores desconhecem as potencialidades do fórum on-line. Além disso, evidencia um não cumprimento do contrato didático (Chevallard, 1988 citado por Silva B., 2002), e reforça a idéia de que para esses professores, o fórum serve apenas para o aluno postar suas tarefas, ignorando o recurso como um meio propício para uma interação colaborativa na construção de conhecimento.

Para aqueles que admitiram encontrar dificuldades, observou-se que essas se relacionavam a falta de experiência com a ferramenta, a concepção de fórum como um repositório de atividades, ao equívoco de confundir o chat com o fórum e até mesmo a ausência de conhecimento sobre o funcionamento do recurso, como foi observado na atitude de um dos dois professores que não postou sequer 01 mensagem em seu fórum. 
Ao ser questionado, na entrevista, pela falta de retornos aos seus alunos, respondeu:

"Ah, já vou logo te avisando, eu não tenho aberto o fórum porque ele só abre lá na coordenadoria de educação a distância" (Entrevista, Professor G, 01/abril/05). A dificuldade apresentada por esse professor mostrou uma concepção equivocada de fórum, e o desconhecimento do seu funcionamento, além de um certo descaso da relevância da interação para com os alunos, caracterizando, uma ruptura do contrato didático. Esse professor mostrou desconhecer as características e a assincronicidade do curso on-line (Palloff e Pratt, 2004). O outro professor que não interagiu no fórum, ao ser questionado, ele afirmou que ainda não havia trocado mensagens no fórum por problemas de ordem familiar.

A oitava questão tratou especificamente da interação dos professores nos seus respectivos fóruns. A tabela 3 apresenta as formas de interação classificadas em 09 (nove) categorias para fins de análise.

Tabela 3- Questão 08: “Como foi a sua interação no fórum?”

\section{Tabela 3- Questão 08: “Como foi a sua interação no fórum?”}

\begin{tabular}{l|c|c|c|c|c|c|c|c|c|c} 
Professores $\rightarrow$ & A & B & $\mathbf{C}$ & D & E & F & G & H & I & J \\
Interações $\downarrow$ & & & & & & & & & \\
\hline Trabalho em grupo & $\mathrm{x}$ & & & $\mathrm{x}$ & $\mathrm{x}$ & & & & $\mathrm{x}$ & \\
\hline Postagem de atividades e dúvidas & $\mathrm{x}$ & $\mathrm{x}$ & $\mathrm{x}$ & $\mathrm{x}$ & $\mathrm{x}$ & & & $\mathrm{x}$ & $\mathrm{x}$ & $\mathrm{x}$ \\
\hline Uma resposta para todos & $\mathrm{x}$ & $\mathrm{x}$ & $\mathrm{x}$ & $\mathrm{x}$ & $\mathrm{x}$ & & & $\mathrm{x}$ & & \\
\hline Resposta individual ao aluno & $\mathrm{x}$ & & & $\mathrm{x}$ & $\mathrm{x}$ & & & $\mathrm{x}$ & $\mathrm{x}$ & \\
\hline Usou mais o e-mail & & & & $\mathrm{x}$ & & & & & $\mathrm{x}$ & \\
\hline Usou mais o chat & & & & & & & & & & $\mathrm{x}$ \\
\hline Incentivo à réplica e tréplica & & & & & $\mathrm{x}$ & & & & & \\
\hline Construção de texto coletivo & & & & $\mathrm{x}$ & $\mathrm{x}$ & & & & $\mathrm{x}$ & \\
\hline Estímulo às discussões e debates & $\mathrm{x}$ & & & $\mathrm{x}$ & $\mathrm{x}$ & & & $\mathrm{x}$ & $\mathrm{x}$ & $\mathrm{x}$ \\
\hline Nenhuma interação & & & & & & $\mathrm{x}$ & $\mathrm{x}$ & & &
\end{tabular}

Os resultados mostraram que 03 (três) professores interagiram de forma não satisfatória no fórum, isto é, apenas para a postagem das atividades, e deixaram de responder dúvidas e solicitações de alguns alunos (B, C e J) e 2 (dois) não interagiram (F e G).

Um (01) professor (E) utilizou o fórum para provocar discussões, apresentou a réplica e tréplica às questões debatidas pelos alunos, fato já evidenciado nas análises da questão 2 e 04 (quatro) utilizaram-no para postagem das atividades e dúvidas, estimularam a interação e deram retornos aos questionamentos, além disso, incentivaram o trabalho em grupo (A, D, E e I).

Comparando-se a análise da questão $8 \mathrm{com}$ as duas primeiras (a questão 01 e 02), evidencia-se novamente que a alegada experiência de utilização do fórum não garantiu, em 
suas práticas pedagógicas, uma utilização de fórum coerente com a necessidade de interação que caracterizasse uma aprendizagem colaborativa. Em outras palavras, embora a maioria dos professores tenha afirmado que já havia utilizado o fórum, eles não usufruíram as potencialidades desse meio como um ambiente de aprendizagem nessa modalidade de educação e apresentaram, na prática, uma concepção de fórum apenas como um recurso comunicacional. A maioria dos professores não buscou manter o interesse dos alunos com interações assíduas no ambiente on-line como recomenda Palloff e Pratt (2004).

As análises dos resultados das questões 01,02 , e 08 evidenciaram que, no geral, embora eles reconheçam que esse meio possibilita maior grau de interação em relação aos outros recursos, o reduzido número de mensagens postadas no fórum e, conseqüentemente, a pouca interação apresentada pela maioria dos professores, são evidências de que o fórum foi um recurso utilizado de forma inadequada no curso em estudo e não teve todo o seu otencial explorado no sentido de valorizar a interatividade para efetivar a aprendizagem.

Esses resultados mostraram que a falta de uma interação mais efetiva pela maioria dos professores pode ter provocado uma ruptura do contrato didático, levando alguns alunos a usar outros meios (o uso do telefone e reunião presencial com a coordenação) para buscar respostas aos seus problemas de interação no fórum on-line, e reclamar da falta de participação de alguns professores que não interagiram. Embora Chevallard (2001) afirme que a ruptura do contrato pode resultar em aprendizagem, Silva B. (2002) contrapõe ao afirmar que essa ruptura pode também levar a fracassos escolares.

\subsection{Análises dos resultados das entrevistas com os alunos}

Para mostrar as opiniões dos alunos com relação às interações vivenciadas no fórum online do curso investigado optou-se pela análise das respostas da questão 07 do questionário dos alunos, porque essa questão investigou a interação de forma mais significativa e a relevância do fórum na opinião deles. A Tabela 04 mostra que para 24 (vinte e quatro) alunos o fórum on-line contribuiu bastante para a interação entre professores e alunos. Portanto, para a maioria dos alunos o fórum permitiu uma interação satisfatória entre professores e alunos.

\section{Tabela 4 - Questão 07 - "Na sua opinião o fórum contribui para a interação entre professor e aluno?"}

\begin{tabular}{l|c|c} 
Respostas & Alunos & Percentagem $(\%)$ \\
\hline Bastante & 24 & 75 \\
\hline Pouco & 07 & 22 \\
\hline Nada & 01 & 3 \\
\hline Total & 32 & 100
\end{tabular}

Dos 32 (trinta e dois) alunos que responderam essa questão, 07 argumentaram que essa contribuição foi pouca e para 01 (um) aluno não houve contribuição do fórum na interação com o professor. $\mathrm{O}$ depoimento dos 07 alunos que apontaram a interação no fórum como insuficiente foi confirmado ao longo do curso pela observação do fórum das disciplinas. A análise da questão 07 (sete) mostrou que, 31 (trinta e um) alunos consideraram vantajosa a utilização do fórum, embora as interações observadas com os professores no ambiente 
tenham sido reduzidas na maior parte dos fóruns e até mesmo com os outros alunos. Esse resultado mostra que os alunos também desconhecem o seu papel e a sua responsabilidade em colaborar e gerenciar o processo de aprendizagem enquanto mantenedores e formadores de uma comunidade de aprendizagem on-line, como sugerem Palloff e Pratt (2004).

Uma concepção de uso do fórum inadequada foi evidenciada por 01 aluno que negou a contribuição do fórum alegando que a interação não aconteceu porque o professor não deu retorno no fórum. Esse aluno também não cobrou dos professores essa interação (respostas) e nem procurou junto à coordenação do curso uma solução. Essa ausência de exigência mostra o desconhecimento do seu papel no fórum, e de certa forma o não cumprimento do contrato didático. Strong e Harmon (1977), citado por Palloff e Pratt (2004), afirmam que os alunos de um programa a distância procuram cursos que tenham, entre outras características, foco no aluno e não no professor, bom custo benefício, ambiente tecnológico confiável, fácil navegação além de interação e informação adequadas. Eles argumentam que, se esses alunos não se sentem atendidos, eles podem ficar frustrados e desistir do programa ou do curso.

A falta de autonomia para debater, no fórum, a ausência das mensagens do professor mostrou que, de um modo geral, os professores não criaram uma comunidade de aprendizagem on-line e que os alunos também desconheciam suas atribuições de colaboradores no sentido de provocar a interação entre eles mesmos, porque houve uma ausência de mensagens dirigidas entre os próprios alunos descaracterizando uma aprendizagem colaborativa (Palloff e Pratt, 2004). A aceitação implícita dos alunos pela falta de retornos significativos do professor e considerando-se que 24 deles afirmaram que $o$ fórum contribuiu para o alcance dos seus objetivos, mostra que esses alunos concordam com uma prática reprodutivista do modelo presencial de ensino e aprendizagem em que não há cobranças de ambas as partes.

\section{Conclusões}

Os recursos tecnológicos utilizados no curso estudado se constituem meios eficientes e potenciais, mas não têm garantido a necessária interação em face do despreparo dos professores e alunos. O estudo realizado mostrou que os sujeitos analisados não possuíam um perfil de autonomia adequado que se requer para a utilização de todas as potencialidades desses recursos em ambientes de aprendizagem on-line em que as interações são fundamentais para o estudante. Essa inadequação foi observada nas concepções dos sujeitos investigados sobre o uso do fórum on-line, caracterizando-o como repositório de atividades e não havendo da maioria o reconhecimento de que esse ambiente é um importante recurso para a interação e construção coletivas do conhecimento através da aprendizagem colaborativa.

A maioria dos professores apresentou um perfil que se enquadra em apenas uma ou outra das três dimensões identificadas por Belloni (2001), evidenciando uma prática reprodutivista importada do ensino presencial. A formação continuada e específica para atuar na EAD, o preparo para o uso do fórum on-line, merece atenção e pode contribuir para a melhoria na qualidade dessa modalidade de educação.

Embora as evidências apontadas se refiram a um curso em particular, uma parte da equipe dos professores (03) tinham formação e prática em cursos a distância de outra instituição, enquanto outros (05), em seus depoimentos, afirmaram que não tinham formação acadêmica nessa modalidade de ensino, apenas experiências em EAD, de onde se conclui que essas práticas não se restringem ao curso investigado. 
Espera-se que a esses resultados somem-se outros que contribuam para fomentar discussões que favoreçam a construção de modelos para cursos de EAD, com propostas metodológicas específicas para essa modalidade de ensino e que potencialize o uso dos recursos da informática, da interação no fórum on-line, no sentido de contribuir para a mudança das atuais concepções desse meio, entre os professores que atuam em cursos a distância.

Esses resultados sugerem a necessidade de promover debates e novos estudos que tragam soluções para os problemas evidenciados em relação à interação entre professores e alunos em ambientes virtuais de aprendizagem e que contribuam para a transformação de suas concepções de fórum on line baseadas em suas experiências e práticas presenciais.

Que os projetos pedagógicos dos cursos de instituições autorizadas a oferecer EAD no país, tragam em seu bojo, a relevância das interações entre os sujeitos que participam do sistema didático (alunos e professores), possibilitando a formação de estudantes comprometidos com a construção do seu conhecimento e não apenas como receptores ou transmissores de informações.

É preciso também viabilizar esforços e investimentos dos diferentes setores da sociedade no sentido de prover recursos para a formação inicial e permanente que garantam o melhor preparo daqueles docentes que vão atuar na educação a distância, e que são descomprometidos com a formação integral do indivíduo, com seu desenvolvimento social, histórico e cognitivo e que os preparem para promover aprendizagens significativas no ambiente virtual por meio de interações efetivas entre os sujeitos dessa modalidade de educação.

\section{Referências bibliográficas}

ALMEIDA, M. E. B. "Educação a distância na Internet: abordagens e contribuições dos ambientes digitais de aprendizagem". Revista Educação e pesquisa, v. 29, n. 2, p. 327-340, jul./dez. 2003. ISSN 1517 - 9702.

ALMEIDA, M. E. B, PRADO, M. E. B. B e VALENTE, J A (orgs). "Educação a distância via Internet" Editora Avercamp. São Paulo, 2003.

BELLONI, M L. "Educação a distância". Campinas: Autores Associados, São Paulo, 2001. CHEVALLARD, Y. "Estudar Matemáticas: o elo perdido entre o ensino e a aprendizagem". Tradução de Daisy Vaz de Moraes. Porto Alegre: Editora Artmed, 2001. FERREIRA, A B H. "Novo Aurélio - O dicionário da língua portuguesa". Editora Nova Fronteira, $5^{\text {a }}$ impressão. Rio de Janeiro, 1999.

HOUAISS A. "Dicionário da Língua Portuguesa". Editora Moderna LTDA. $2^{a}$ edição revista e ampliada. Rio de Janeiro, 2004.

MORAN, J. M. "Propostas de mudanças nos cursos presenciais com a educação online". texto apresentado no $11^{\circ}$ Congresso Internacional de Educação a Distância. Disponível em: http://www.eca.usp.br/prof/moran/propostas.htm\#utilização. Acesso em 26 de julho de 2006.

"Contribuições para uma pedagogia da educação on-line". In: SILVA, M. (org.). "Educação on-line: teoria, práticas, legislação, formação corporativa". Editora Loyola, p. 39-50. São Paulo. Disponível em:

http://www.eca.usp.br/prof/moran/contrib.htm\#gestao . Acesso em 25 de julho de 2006.

PALLOFF R. M. e PRATT K. "O aluno virtual - um guia para trabalhar com estudantes on-line". Tradução de Vinicius Figueira. Editora Artmed. Porto Alegre, 2004.

SILVA, B. A. "Contrato Didático". In: MACHADO, S. D. A.: Educação Matemática uma introdução. $1^{a}$ reimpressão. São Paulo: Editora da PUC- SP, EDUC, 2002. p. $43-64$. VIGOTSKY, L. S. "A Formação Social da Mente - O desenvolvimento dos processos psicológicos superiores”. Tradução de José Cipolla Neto. São Paulo: Martins Fontes, 2000. 